\title{
Lina, uma criança exemplar! Friedrich Froebel e a pedagogia dos jardins-de-infância
}

\author{
Alessandra Arce \\ Universidade Estadual de Campinas, Faculdade de Educação
}

\section{Introdução}

Friedrich Froebel, filho do pastor luterano Johann J. Froebel e de Jakobine E. Hoffman, nasceu aos 21 dias de abril em 1782, na vila de Oberweissbach, no principado de Schwarzburg-Rudolstadt, região sudeste da Alemanha, e viveu até o ano de 1852. Parte de sua vida transcorreu, portanto, durante o período histórico caracterizado por Eric Hobsbawm (1996) como "A Era das Revoluções” (1789-1848), época da história européia marcada por guerras e revoluções, tais como a Revolução Francesa, a Revolução Industrial, as Guerras Napoleônicas e, finalmente, encerrando o período, as Revoluções de 1848. A "Era das Revoluções" foi também a "Era das Contra-Revoluções": a burguesia precisava ser revolucionária ao lutar contra o feudalismo, mas precisava ser contra-revolucionária, conservadora, ao lutar contra o proletariado e os camponeses. Esse período da história ocidental foi, portanto, marcado por profundas contradições, por uma complexa correlação de forças de luta, por uma grande heterogeneidade quanto aos avanços e aos retrocessos nos campos econômico, político e sociocul- tural. Nesse contexto se situa uma problemática importante para a análise que apresentaremos neste texto: trata-se do processo de separação alienante entre o público e o privado. Pode-se ter uma idéia da gênese desse processo pelas informações apresentadas por Perrot (1991) em seus estudos. A separação entre o público e o privado configurou-se de várias formas, sendo uma delas a nítida demarcação de papéis para o homem (vida pública) e para a mulher (vida privada). A valorização da família, agora nuclear, desempenhou importante papel neste processo: a burguesia encontrou nesta organização privada uma forma de vencer os títulos e a hierarquia dos nobres, elegendo a mulher como rainha do ambiente privado e doméstico. Assim, não por acaso veremos a mulher e a família desempenharem um papel decisivo em toda a obra de Froebel.

Segundo seus biógrafos (Liebschner, 1992; Cole, 1907; Prüfer, 1930), Froebel em sua infância foi lento nos estudos, extremamente introspectivo e empurrado desde cedo para o estudo das coisas práticas da vida. Formou-se na prática e pela prática, auto-educando-se, e quando se tornou professor (após ter sido 
agrimensor e trabalhar com arquitetura) procurou estimular a auto-educação e o auto-aperfeiçoamento dos alunos. Segundo Koch (1985, p. 24), Froebel fez de tudo para encontrar o caminho pedagógico mais aprazível, embora não tenha lido nenhum livro de pedagogia. A solução encontrada foi um mergulho profundo nas próprias experiências escolares, das quais trazia tristes recordações, não desejando sua repetição na vida de outras crianças. Froebel foi um educador nascido da prática, e toda sua metodologia de trabalho foi baseada nela. Blow (1895, p. 37) considera muito importante esta praticidade, este "aprender fazendo" de Froebel. Para esta autora (ardorosa divulgadora de sua obra), ele era um educador nato, e a infância introspectiva o teria ajudado a desenvolver a disciplina necessária para que isso ocorresse. Durante sua juventude, ele já considerava que os homens não necessitavam apenas de pão e instrução, mas também de serem presenteados por si mesmos, objetivo máximo da concepção pedagógica froebeliana.

Este caráter prático de Froebel também foi destacado pela baronesa B. Von Marenholz-Bulöw, que acompanhou durante anos seu trabalho e procurou divulgá-lo por toda a Europa. Em seu livro Reminiscenses of Friedrich Froebel ${ }^{1}$, a baronesa (1877, p. 17) chama a atenção para a dificuldade que ele tinha em entender a linguagem do mundo acadêmico. A cultura apresentada por estudiosos lhe era algo estranho. Sendo autodidata, ele apenas via no mundo acadêmico um criadouro de maledicências e conflitos que em nada auxiliavam na vida cotidiana das pessoas, e em especial na das crianças.

Este educador, que construiu seu conhecimento na prática, era incapaz de imaginar, diante das amarguras impostas pela vida, o quanto suas idéias viriam

${ }^{1}$ Nesse livro a baronesa transcreve os seus diálogos com Froebel, desde seu primeiro encontro, em 1849, até a morte de Froebel, em 1852. A característica marcante dessa obra reside na clareza dos diálogos, por meio dos quais Froebel explicita seu pensamento não somente a respeito da educação, mas também sobre os acontecimentos sociais e políticos do período em que viveu. a afetar o pensamento e o fazer educacional relativo às crianças menores de 6 anos. Froebel foi um dos primeiros educadores a se preocupar com a educação de crianças pequenas, e a importância de sua obra nos é demonstrada sempre que passamos diante de um jardim-de-infância, um kindergarten (em alemão, kind significa criança e garten significa jardim). Não é muito difícil adivinhar por que Froebel denominou assim as instituições voltadas para o trabalho educativo com crianças em idade pré-escolar: para ele, a infância, assim como uma planta, deveria ser objeto de cuidado atencioso: receber água, crescer em solo rico em nutrientes e ter a luz do sol na medida certa. O jardim é um lugar onde as plantas não crescem em estado totalmente silvestre, totalmente selvagem, é um lugar onde elas recebem os cuidados do jardineiro ou da jardineira. Mas o jardineiro sabe que, embora tenha por tarefa cuidar para que a planta receba todo o necessário para seu crescimento e desenvolvimento, em última instância é o processo natural da planta que deverá determinar quais cuidados a ela deverão ser dispensados. Certas plantas não crescem bem quando regadas em demasia, já outras precisam de muita água; algumas plantas precisam de muito sol, ao passo que outras crescem melhor à sombra. $\mathrm{O}$ bom jardineiro sabe "ouvir" as necessidades de cada planta e respeitar seu processo natural de desenvolvimento. Para Froebel, assim também ocorre com as crianças e, portanto, os adultos encarregados da educação delas deveriam comportar-se tal como o jardineiro. Data de 1840, na cidade de Blankenburg, a fundação do primeiro dos muitos kindergartens. Froebel faleceu tendo seus jardins-de-infância proibidos em seu país $^{2}$, mas isso não impediu o estrondoso sucesso de suas idéias, que foram disseminadas pelo mundo por admiradoras de seu trabalho, como a baronesa Von

${ }^{2}$ Froebel teve sua imagem e suas idéias educacionais associadas aos ideais socialistas que eram defendidos por seus sobrinhos Julius e Karl Froebel, e como o governo prussiano lutava contra estes ideais, as escolas de Froebel foram fechadas pelo receio de que os estivessem disseminando. 
Marenholtz-Bulöw (1811-1893), Margarethe Meyer Schurz (1833-1876), Elizabeth Peabody (1804-1894) e Susan Elizabeth Blow (1843-1916), entre outras.

O Brasil acabaria por apaixonar-se por esse educador. Atualmente, no campo dos estudos de história da educação infantil e de suas instituições, muitos estudiosos procuram resgatar o florescer das idéias froebelianas em nosso país. Autores como Kuhlmann (2001a e 2001b), Kuhlmann e Barbosa (1998), Bastos (2001), Monarcha (2001), Pinazza (1997), Kishimoto (1986), entre outros, trazem com seus trabalhos detalhados e exaustivos a tentativa de reconstrução da história do atendimento a crianças menores de 6 anos no Brasil. Dentre as fontes de pesquisa destes autores se destaca a Escola Caetano Campos, em São Paulo, onde foi fundado o primeiro jardim-de-infância público do país, anexo à Escola Normal, organizado por Gabriel Prestes. A escola contava com uma equipe grande de professoras que se dedicaram a traduzir alguns trechos das obras de Froebel, primeiramente do próprio alemão e em seguida das traduções inglesas. Foi grande o legado do jardim-de-infância da Escola Caetano Campos para a educação infantil, e a Revista do Jardim-de-infância (publicada de 1896 e 1897) é um exemplo disso. Nela, Gabriel Prestes e suas colaboradoras traduziram e divulgaram trechos de vários trabalhos sobre os jardins-de-infância e de obras de Froebel, Blow e Peabody. Houve também um trabalho de adaptação de cantos e ocupações para a realidade brasileira. A revista, organizada em dois volumes, é uma importante fonte de estudos a respeito das rotinas e modificações realizadas na metodologia froebeliana em sua entrada no Brasil.

Todavia, ainda há uma carência de estudos mais detalhados das obras de Froebel. Esta lacuna se deve em parte ao fato de quase não existirem obras deste autor traduzidas para o português. No intuito de contribuir para a reconstrução da história da educação infantil e tornar Friedrich Froebel conhecido entre os educadores, debrucei-me sobre sua obra e a de seu mestre Pestalozzi em minha tese de doutoramento, já publicada em livro (Arce, 2002a). Produzi ainda outro livro, de caráter mais didático (Arce, 2002b), apre- sentando as principais idéias educacionais de Froebel. O presente artigo, portanto, deriva dos estudos realizados. No ano passado, fomos presenteados com a tradução, feita por Maria Helena C. Bastos, da principal obra filosófica de Froebel, A educação do homem. No entanto, como realizei todos os meus estudos com base nas obras inglesas traduzidas do alemão, optei por manter este artigo fiel aos trechos utilizados em minha tese. Indubitavelmente, devido à dificuldade de acesso às obras inglesas e aos originais em alemão, recomenda-se ao leitor que deseje ler $A$ educação do homem recorrer à tradução em português agora existente.

$\mathrm{O}$ artigo ora apresentado dedica-se a realizar uma análise (ainda preliminar) de um importante texto de Froebel, encontrado no livro Pedagogia do jardimde-infância (1917), intitulado "De como Lina aprendeu a escrever e a ler: uma bonita história para crianças que gostam de estar ocupadas". A justificativa para a análise deste texto em particular é que nele as idéias pedagógicas de Froebel aparecem “em ação", isto é, concretizadas numa narrativa do processo pelo qual uma mãe ensina sua filha a escrever. Este artigo foi dividido em três partes: a primeira é dedicada a uma exposição da história de Lina; a segunda apresenta a explicitação de algumas das categorias por meio das quais o autor pensava e fazia a educação infantil, e que estão presentes no texto; por fim, a terceira parte conclui o trabalho com alguns questionamentos críticos voltados para a pedagogia froebeliana e os papéis atribuídos a família, criança e mulher nesse contexto, ressaltando-se a importância de Froebel como um dos precursores do movimento escolanovista.

\section{“De como Lina aprendeu a escrever e a ler: uma bonita história para crianças que gostam de estar ocupadas"}

Este texto encontra-se no livro Pedagogics of the kindergarten (Froebel, 1917), nas páginas 286 a 337. Por que Froebel apresenta essa história sobre uma mãe ensinando sua filha a escrever, se o livro é dedicado à pedagogia dos jardins-de-infância? Porque Lina é 
apresentada por Froebel como um modelo do que seria a criança que se educou em um jardim-de-infância: doce, meiga, curiosa e, como o próprio título afirma, que adora estar ocupada. Ela possui uma família em harmonia perfeita, devotada à religião e à moral. A mãe procura sempre mostrar à sua pequena filha o universo como fruto de uma unidade entre o homem, a natureza e o divino. Lina já passou pelo jardim-deinfância e está em casa aguardando o momento de iniciar o processo formal de escolarização. Froebel inicia esta pequena história descrevendo sua personagem central da seguinte maneira:

Lina era uma garotinha de mais ou menos 6 anos de idade que gostava de se ocupar independentemente. Ela conseguia realizar muitas coisas com brinquedos simples; conseguia construir muitas coisas bonitas com cubos e blocos; e posicionar muitas coisas com tabletes de formas e cores diferentes, com varetas etc. Ela conseguia fazer muitas coisas bonitas de várias formas, colocando juntas varetas coloridas, tiras de papel e outros materiais; produzia, dessa maneira, muitas coisas com esses pequenos materiais para brincar, os quais lhe eram muito queridos. Lina era capaz também de facilmente pegar a bola, e tinha por este meio adquirido tal destreza e tal controle do corpo - tal uso talentoso de seus membros - que ela não deixava nada cair facilmente, nem desajeitadamente. Lina também sabia muitas canções bonitas e sabia cantá-las adequadamente. Ela conseguia acompanhar muitas de suas brincadeiras com as canções, o que aumentava seu prazer, porque elas a instruíam para o que ela estava fazendo, e então ela não precisava estar sempre perturbando o pai e a mãe perguntando “o que é aquilo?", "por que é assim?". Dessa forma, Lina estava sempre alegre e ativa, porque não sentia o tempo pesar, não existia mau humor em sua vida, ao contrário, porque sempre estava contente e animada, ela sempre foi o deleite especial de seus pais, assim como um exemplo para outras crianças, as quais gostariam de ser o mesmo para os seus pais, e também gostam de brincar e são felizes de forma viva, ordenada e ativa. (Froebel, 1917, p. 286, trad. minha)

Lina mora com sua mãe e seu pai. A mãe de Lina é a própria imagem do papel social e educativo atri- buído à mulher na pedagogia de Froebel. Neste aspecto, o educador alemão reproduzia um ideal de mulher e de mãe que vinha sendo fortemente difundido naquela época. Um exemplo nesse sentido é o trabalho de Jules Michelet (1798-1874), uma das figuras intelectuais mais destacadas da Europa durante o século XIX. Historiador e autor do famoso livro $A$ mulher (Michelet, 1985), ele referenda e divulga o ideal burguês e religioso para a mulher daquela época: mãe/esposa zelosa. Nesta obra, ao discutir se o lugar ideal para a mulher seria na vida pública ou privada, o autor defende que as mulheres não servem para o trabalho na vida pública. Tomando as mulheres trabalhadoras como exemplo, ele afirma que elas jamais substituirão o homem, pois não possuem condições físicas para tanto; por isso o ambiente familiar lhes figura como o mais seguro e natural. O autor aprofunda esta questão ao afirmar que a mulher não pode viver sem o homem e os filhos não podem viver sem a mulher; a família é um dado natural, e qualquer de seus membros que tenha de sobreviver sozinho não o conseguirá e perecerá. Portanto, sendo feita para o lar, essa mulher deve ser a inspiração do homem; ela deve ser graciosa - "a graça é um reflexo do amor sobre um fundo de pureza. A pureza é a mulher mesma" (Michelet, 1985, p. 89). Ela representa, assim, tudo de mais doce que possa existir; "a mulher é o domingo do homem"(idem, p. 253); a alegria, a liberdade, a festa, toda a emoção doce e divina está nela encerrada. Sendo o homem incapaz de tanta doçura, ele necessita da mulher. A mãe de Lina encerra todos esses predicados.

A mãe cuida dos afazeres domésticos, é responsável pelo ambiente familiar que transpira amor e delicadeza graças à sua dedicação. Nas horas vagas, a mãe dedica-se integralmente à pequena filha, procurando atender a seus desejos e necessidades. $O$ pai está fisicamente ausente na maior parte da história, mas jamais sai do pensamento e do coração da pequena Lina. Como trabalha o dia todo, só à noite ele retorna ao lar, apresentado por Froebel como um refúgio de tranqüilidade e amor. Carinhoso com sua doce filha, o pai também procura participar de seu desen- 
volvimento, mas é coadjuvante nesse processo. Temos ainda a figura do tio, que se supõe ser solteiro já que almoça e janta com a pequena família todos os dias. O tio não reside com eles. Ele também procura acompanhar o desenvolvimento de Lina.

A história tem seu desencadeamento quando o pai de Lina recebe uma carta que a menina, muito curiosa, deseja ver. A escrita da carta leva-a a uma incontrolável vontade de aprender como se escreve. Ela pede insistentemente à sua mãe que a ajude a escrever. A mãe, sempre muito solícita e atenta aos desejos e necessidades de sua pequena filha, concorda. Para iniciar a aprendizagem, ela chama a atenção de Lina para o fato de que em uma carta as pessoas escrevem seus nomes ao final da mesma e no envelope. Nada mais justo, portanto, que iniciem a aprendizagem da escrita pelo nome de Lina. A mãe, neste processo, parte do reconhecimento dos sons presentes no nome. Somente em um segundo momento é que ela representa os mesmos por meio das letras. Para isso a mãe aproveita as varetas com as quais Lina brincava. Após repetidos exercícios de representação por meio destas, a mãe oferece a Lina o lápis (ou melhor, um giz de cera) e a ardósia (pedra muito utilizada na época de Froebel para o ensino da escrita). O papel aparece em um terceiro momento. Vejamos abaixo um pouco deste processo.

"Mas você sabe, filha" - continuou a bondosa mamãe "que quando seu pai manda uma carta ele sempre escreve o nome dele no final dela, e por fora ele escreve o nome de quem irá recebê-la? Então, minha Lina, você deve em primeiro lugar aprender a escrever seu nome - isto é, aprender a colocá-lo com varetas. Agora, qual é o seu nome?"

"Ah, você sabe isso; meu nome é Lina."

"Eu sei seu nome, certamente" - disse sua mãe - "Mas se você deseja escrevê-lo, ou colocá-lo com varetas, devemos ouvi-lo cuidadosamente, e dar atenção para as diferenças entre sons fechados e abertos que notarmos nele. Devemos aprender a conhecer os sinais abertos ou fechados, para que possamos colocar essas letras uma ao lado da outra, do jeito que ouvimos os sons abertos e fechados seguirem uns aos outros no seu nome.” (Froebel, 1917, p. 287, trad. minha)
Rapidamente Lina aprende seu nome e tornase capaz de representá-lo. Durante o jantar ela exibe para o pai e o tio sua conquista, que é festejada por todos. O tio de Lina, extremamente perspicaz, sugere um desafio para o próximo dia, envolvendo uma palavra que representa a pessoa responsável pelo lar: sua mãe.

Quando todos estavam à mesa, o tio de Lina disse: “A mamãe querida cuida de todos nós; primeiro ela ajuda Lina, e agora ela cuida para que nosso jantar não esfrie. Você nos deu hoje, Lina, um grande prazer por ter representado e lido seu nome; amanhã nos dê outra alegria, colocando e lendo a bonita palavra "mamãe"”. "Você está certo, meu querido tio" - disse a criança. E todos na mesa ficaram tão felizes e contentes quanto se tivessem celebrando um aniversário. No dia seguinte, a hora que a mamãe cuidadosa devotava à sua criança mal tinha chegado quando esta veio até ela, insistente: "Por favor, me ensine hoje a colocar a palavra 'mamãe', para que eu possa agradar novamente o papai e o titio quando eles chegarem em casa..."

(Froebel, 1917, p. 290, trad. minha)

Assim, sucessivamente Lina aprende as palavras “mãe", "pai" e "tio". Neste momento da história seu pai necessita viajar, e este fato causa a Lina imensa tristeza, mas, ao mesmo tempo, desperta-lhe outro desejo: o de escrever uma carta para seu pai. A mãe, com a ajuda do tio, realiza seu desejo. A primeira carta é escrita por Lina com a ajuda da mãe, na ardósia, contendo as seguintes palavras: "Querido papai, por favor, volte para casa logo. Eu já consigo escrever na ardósia. Da sua querida Lina" (Froebel, 1917, p. 300, trad. minha). Todavia, enviar a ardósia não seria possível, então o tio surpreende Lina dando-lhe um pedaço de papel para que ela copiasse o conteúdo desta pequena carta. Feito isto, a carta foi imediatamente remetida para o pai. Este, entusiasmado com o avanço da filha, propõe outro desafio; junto com a correspondência lhe envia um pequeno livro com figuras e textos.

Lina fica extasiada com o pequeno livro, sentase em um canto de seu quarto e folheia-o incessantemente, voraz por compreender sua história. Neste mo- 
mento sente-se frustrada, pois não consegue identificar as letras do livro, elas são diferentes das conhecidas anteriormente (o livro foi impresso em alfabeto gótico, e Lina vinha aprendendo a escrever com letras maiúsculas romanas). Mais um desafio surge e a menina corre para a mãe buscando ajuda. A mãe, por sua vez, explica-lhe que as figuras do livro também contam a história, sendo o desenho um importante meio de representarmos nossos pensamentos e nossas palavras. Lina volta-se para as figuras, devorando-as e decifrando-as. Após esta etapa, a mãe começa a mostrar-lhe que as letras do livro não são tão diferentes das já aprendidas. Froebel passa, então, a revelar todo o longo exercício de reconhecimento, nas letras góticas, das letras maiúsculas romanas anteriormente aprendidas por Lina. Novamente vemos Lina vencer outro desafio.

Nesse momento da narrativa, Lina, juntamente com sua amiguinha Mina, vai visitar o jardim-de-infância que ambas freqüentaram. A "jardineira” (muito ligada à família, pois para Froebel família e escola deveriam sempre trabalhar juntas), sabendo dos avanços da menina, pede que ela compartilhe sua experiência com as outras crianças. Encantadas com a colega, as crianças procuram imitá-la, e a jardineira aproveita-se desse interesse tão intenso para auxiliar mais uma vez as crianças em suas buscas. Esta motivação interna das crianças para aprender a escrever modifica todas as atitudes e o ambiente da escola. A jardineira, tal qual a mãe de Lina, não interfere, apenas procura ser o mais útil possível para que as crianças satisfaçam com prazer e alegria suas necessidades.

Vencida a etapa de leitura do livro, o tio propõelhe outra atividade: a de reescrever a história do livro em uma carta para seu pai. Assim ele saberia que ela realmente leu o livro. Lina põe-se a trabalhar incansavelmente neste novo projeto, sendo bem-sucedida. Contudo, considera sua carta muito grande, sua letra também, e pede para sua mãe ensinar-lhe agora a escrever como ela, o tio e o pai o fazem. A mãe, então, diz à criança que chegou o momento de ela entrar na escola, pois de agora em diante o processo de aprendizagem exigiria mais atenção e cuidados, sendo necessário um tempo bem maior do que aquele que a mãe lhe dedicava diariamente. E assim Froebel termina sua história: Lina passa a aguardar, lendo livros de historinhas, sua entrada na escolarização formal.

\section{A educação pelo desenvolvimento de Froebel: alguns de seus princípios educacionais}

A pequena história criada por Froebel, acima resumida, apresenta-nos de maneira condensada os principais pontos de sua teoria educacional. Tendo Lina já passado pelo jardim-de-infância, Froebel procura apresentar o comportamento e a atitude dessa menina como um exemplo do tipo de criança que ele desejava formar (desenvolver) naquela instituição. Lina é independente, autodidata, curiosa, ativa, alegre, meiga e livre. Este fato se deve ao respeito por sua individualidade e à busca de uma educação que acompanhe o desenvolvimento infantil, respeitando-o e nutrindoo desde cedo. Entretanto, não só o jardim-de-infância teve e tem um papel fundamental na formação da criança. A família também é essencial. A de Lina, como vimos, era extremamente integrada, harmoniosa e preocupada com sua educação. Viver em família é, para Froebel (1887, p. 25-26), o primeiro exercício de viver em comunidade, uma comunidade de amor, regada pela religiosidade, uma comunidade que está contida dentro de todo o rebanho divino. É importante ressaltar que a pedagogia de Froebel é fortemente marcada por um tipo de filosofia cristã, na qual Deus, a natureza e o ser humano formam uma unidade que seria o fundamento de toda a existência.

Dentro deste espírito, os pais devem possuir uma moral inabalável e ser despertados para a importância de seu papel na formação dos filhos, devendo buscar sempre um meio para a harmonização da tarefa educativa com o caráter que envolve a paternidade e a maternidade. Isto é, assim como a relação de Deus para com os seres humanos é uma relação do Pai com seus filhos, a relação dos pais terrenos com seus filhos deve ser a de educar as crianças e os jovens para que, quando crescerem, relacionem-se com Deus da maneira virtuosa como aprenderam a relacionar-se 
com seus pais. No interior dessa perspectiva da família como mediadora entre a criança e Deus, Froebel atribui especial importância ao papel da mãe, dedicando-lhe uma obra inteira, em que a mãe é personificada nesta personagem cheia de bondade, amor e ternura, totalmente esvaziada enquanto indivíduo imagem essa que foi sendo construída pela sociedade burguesa com a ajuda da religião (tanto a protestante quanto a católica), e que é tão bem exemplificada pela mãe de Lina. O livro The mottoes and commentaries of Friedrich Froebel's mother play (1895), de Froebel, traz, logo em suas primeiras páginas, uma exaltação da maternidade, que é a união da mãe e da criança, a qual constitui a semente do bem, a semente de tudo o que de mais nobre existiria no ser humano. A criança é a razão de vida da mulher e seu tesouro, seu bem mais precioso. Durante todo o livro, Froebel exortará a mãe a tratar seu filho como centro e razão principal de sua vida, cumprimento pleno de seu destino como ser humano. Por isso, já nos comentários iniciais ele chama a mãe a admirar o presente que Deus lhe deu e a sentir que Ele nela confiou, dando-lhe naturalmente, instintivamente, tudo o que ela precisa para cuidar desta maravilha divina posta em seus braços. Em minha dissertação de mestrado (Arce, 1997) formulei uma análise crítica das conseqüências para a educação infantil da imagem da mulher como mãe e educadora nata, agraciada com o dom divino do amor maternal.

Segundo Froebel (1887, p. 69-70), a mãe desempenharia um papel primordial nesta pequena comunidade, a família. A mãe criaria na criança o espírito cristão, seria ela quem o estimularia através do amor com o qual inunda o ambiente familiar, auxiliando dessa maneira o desenvolvimento interno da criança de acordo com os desígnios divinos e em harmonia com os mesmos.

Assim, sob o comando da mãe, a família deve ser conduzida em um ambiente pleno de amor e religiosidade. Aos pais cabe viver por suas crianças. Elas são o centro da vida familiar e têm muito a ensinar, pois trazem dentro de si os germes do divino, do que existe de mais puro no ser humano. "Venham, deixe- mo-nos viver com as nossas crianças!" não é somente o lema das escolas de Froebel, mas também o lema que a família deve adotar ao se deixar levar por suas crianças, vivendo por elas. Lina e sua família são modelos deste ideal perseguido por Froebel: Lina é o centro de sua família, que procura acompanhar seu desenvolvimento, buscando satisfazer suas necessidades.

Contudo, as atitudes e a personalidade de Lina revelam muito sobre como Froebel pensava a educação. Segundo ele (1902, p. 4-6), quando Lina manifesta o desejo intenso de aprender a ler e a escrever está, ao mesmo tempo, exteriorizando sua vontade de integrar-se ao mundo que a rodeia. Esse perceber-se a si mesma como integrante de um todo maior é o ponto de partida para a germinação do desenvolvimento e da educação da criança como ser humano. $\mathrm{O}$ bom resultado da educação está intimamente ligado a este sentimento, o qual deve ser cuidado e cultivado desde cedo. Quando isso ocorre, a criança, segundo Froebel, exterioriza seu mundo interior, reconhecendo-o como parte de um todo integrado composto pela natureza, por Deus e pela humanidade. Esta relação entre Deus, natureza e humanidade era representada por Froebel (1887) por meio de um triângulo, que simbolizava uma tríade inseparável denominada "Unidade Vital", na qual a educação deveria estar alicerçada para poder conduzir o indivíduo ao desenvolvimento pleno. Dentro do princípio da "Unidade Vital", os processos de interiorização e exteriorização eram fundamentais, pois levavam à clarificação da consciência: ao autoconhecimento, ou seja, à educação. A formação e o desenvolvimento ocorrem graças ao que a criança recebe do mundo exterior, mas só se efetivam quando se sabe, por assim dizer, tocar no seu mundo interior. Este processo, chamado de interiorização, consiste no recebimento de conhecimentos do mundo exterior, que passam para o interior seguindo sempre uma sequiência que deve caminhar do simples ao composto, do concreto para o abstrato, do conhecido para o desconhecido. A atividade e a reflexão são os instrumentos de mediação deste processo nãodiretivo, o que garante que os conhecimentos brotem 
e sejam descobertos pela criança da forma mais natural possível. O processo contrário a este é chamado de exteriorização, no qual a criança necessita trabalhar em coisas concretas como a arte e o jogo, excelentes fontes de exteriorização. Uma vez exteriorizado o seu interior, a criança passa a ter autoconsciência do seu ser, passa a conhecer-se melhor: é assim que a educação acontece. Esta conexão que se estabelece entre o interno e o externo é ponto fundamental para o processo educacional, tanto que Froebel elege este princípio como uma das leis fundamentais da educação.

Se observarmos como Froebel descreve o processo de alfabetização de Lina, veremos que a mãe se utiliza desta lei do autor para ensinar sua filha a ler e a escrever. Não por acaso, a mãe inicia o processo de alfabetização pelo próprio nome de sua filha, pedindo para que Lina primeiro pense nele, o que aumenta seu desejo de representá-lo na forma escrita. Mas a mãe ainda exige um passo intermediário, que é o de pronunciá-lo várias vezes em voz alta, para depois registrá-lo na forma escrita. A mãe procura, com este exercício, fazer Lina perceber a conexão existente entre o interno/invisível (seu nome enquanto representante de sua personalidade) e o externo/visível (a representação deste, através da palavra falada e depois escrita, expressando seu ser).

Lina deseja aprender a escrever, a mãe procura satisfazer este desejo de sua criança, sabendo que escrever é gravar uma memória, um pensamento (por isso originalmente e puramente interno e invisível) expresso de forma audível (por isso perceptível, embora extinguindo-se no momento em que é percebido), conectando-o com o visível, daí a necessidade de sinais que o representem. Como foi mencionado na história, a mãe inicia este processo utilizando-se do nome da criança. O que estaria a mãe querendo obter ao iniciar desta forma? Primeiramente, ela quer da criança a reflexão e o entendimento de sua própria personalidade expressa em seu nome, sua identificação enquanto ser humano. Assim, ela pede à criança que sinta este nome como seu. Esta é a referência principal da criança no mundo. Este exercício é realizado de maneira interna e invisível. Este é o primeiro passo. Entretanto, a criança deseja escrever seu nome, este desejo ex- pressa a vontade de conectar este representar interno e invisível de sua personalidade com o externo visível. Este é o segundo passo. Como a mãe realiza esta vontade? Ela deixa a criança pronunciar várias vezes seu nome em voz alta, aumentando o desejo de registrá-lo na forma escrita. Este é o terceiro passo. O que é falar? Tornar o pensamento interno perceptível. E o que representa a palavra nesta afirmação? É o intermediário entre o puramente interno e o completamente externo (a escrita). Ela une a natureza e as propriedades de ambos, pensamento e escrita, conectando-os assim. A mãe de Lina encontra assim um segredo da educação pelo desenvolvimento, qual seja, o da conexão possuída por todas as coisas. Esta lei das conexões é fundamental na vida humana e na educação que se faça pelo desenvolvimento. (Froebel, 1902, p. 30)

Entretanto, o primeiro passo para que este processo se inicie deve sempre ser dado pela criança. Ao adulto cabe apenas satisfazer ou incentivar a sua curiosidade natural. Por isso, um dos mais importantes princípios da pedagogia froebeliana é o da auto-atividade livre. A criança precisa ter uma mente ativa e livre para poder abrir as portas do conhecimento. Ela deve ser livre para explorar, escolher, questionar e agir. A aprendizagem deve sempre partir daquilo que a criança já conhece. Ouvir o conhecimento da criança é o principal requisito para o sucesso da educação. A liberdade, para Froebel, era o oposto da força e do medo, estando ligada ao amor que deveria presidi-la. Esta era uma das principais mensagens de Froebel para os professores, pois a grande influência destes viria do amor: sem a emoção, a personalidade se fecharia e o sopro vital e divino esmoreceria. Neste ponto, Froebel ressalta que a disciplina não deve ser controlada por castigos físicos; o professor deve levar a criança a internalizar a disciplina e ser capaz de, sozinha, perceber e avaliar seus atos, para só então modificá-los. Por isso sua mensagem dirigia-se sempre às mulheres enquanto educadoras. As mulheres, possuidoras da capacidade biológica da maternidade, possuiriam o amor na forma mais pura, sendo as únicas naturalmente aptas para educar com liberdade e amor, respeitando o desenvolvimento natural da criança, pois assim elas já o faziam há séculos em seus 
lares. A mãe de Lina incentiva-a o tempo todo e a deixa livre para descobrir e explorar o que deseja, sendo apenas um agente auxiliar no processo de aprendizagem de sua filha, colocando em movimento esses princípios tão caros à teoria froebeliana.

Ressaltamos ainda que a ação é parte integrante e indivisível de todo este processo. Agir pensando e pensar agindo era, para Froebel, o melhor método para evitar que o ensino por demais abstrato prejudicasse o desenvolvimento dos talentos das crianças. A atividade levaria a criança à compreensão da tríade (representada pela "Unidade Vital") que guia toda a sua vida, abrindo, portanto, as portas para atingir a perfeição como ser humano. O "aprender fazendo" proposto por Froebel respeita antes de tudo a metodologia natural das crianças. Assim, deve-se "observar, apenas observar, pois a criança mesma te ensinará" (Froebel apud Cole, 1907, p. 26) - eis a máxima que deve reger a educação, porque só assim o professor será capaz de conhecer realmente seu aluno, entendendo sua dinâmica interna e descobrindo sua essência e seu potencial. Froebel considerava que a escola de seu tempo (a escola tradicional) não conseguia perceber a unidade existente entre o universo e a criança, por trabalhar de forma fragmentada e sem vida. $\mathrm{O}$ exterior e o interior estariam justapostos, tornando impossível uma aprendizagem viva. Por isso Koch (1985, p. 55-58) destaca como três pontos fundamentais da metodologia froebeliana os seguintes:

1. A atitude do educador, a qual deveria dar a entender ao educando que ambos estão subordinados à "Unidade Vital". Portanto, o modelo a ser seguido de perfeição humana seria Jesus, por reunir o divino, o humano e o natural, sendo que a liberdade de cada pessoa sempre deveria ser preservada na busca do desenvolvimento de seus talentos. ${ }^{3}$

3 "Por isso, o próprio Jesus, em sua vida e em seu ensinamento, constantemente se opunha à imitação da perfeição externa.
2. O segundo ponto da metodologia froebeliana é relativo ao processo da educação: o homem e a natureza possuem existência em Deus; educar, portanto, é despertar no educando a consciência dessa realidade, orientando-o para uma vida pura e santa. Esse processo ocorre através da exteriorização do interior e da interiorização do exterior, com a ação e a atividade como chaves. Surge aí a necessidade de objetos para que esse processo ocorra, pois a exteriorização mediante matéria concreta, fruto de pensamentos e palavras, é bem mais eficiente do que a realizada por meio de conceitos e palavras abstratas. "Nunca esqueça que o objetivo da escola não é tanto ensinar e comunicar uma variedade e multiplicidade de coisas, mas sim dar destaque à sempre viva unidade que está em todas as coisas" (Froebel, 1887, p. 134-135, trad. minha);

3. Ainda segundo Koch, o terceiro ponto da metodologia froebeliana é relativo à função permanente do educador: respeitar a natureza, a ação de Deus e a manifestação espontânea do educando. A educação deve seguir o livre desenvolvimento, não podendo ser prescritiva, determinista e interventora, pois assim destrói a origem pura da Natureza do educando. Alicerçada na experiência, essa pedagogia se centra na orientação e no despertar da ativida-

Somente a luta espiritual, a perfeição viva, deve ser tomada como um ideal; sua manifestação externa, sua forma não deveria ser limitada. A vida mais elevada e mais perfeita que nós, como cristãos, enxergamos em Jesus - a mais conhecida na humanidade -, é a vida que encontrou a última e primordial razão da sua existência clara e distintamente em seu próprio ser; uma vida que, de acordo com a lei eterna, veio da vida completa, eternamente criadora, atuante e equilibrada. Esta vida perfeita eternamente elevada faria cada ser humano novamente se tornar uma imagem similar ao ideal eterno, para que cada um novamente pudesse se tornar um ideal semelhante para ele próprio e para os outros, faria cada ser humano se revelar auto-ativo e livre de acordo com a lei eterna" (Froebel, 1887, p. 12-13, trad. minha). 
de espontânea da criança, disseminando qualidades e aniquilando defeitos, através do desenvolvimento pleno da harmonia entre homem, Deus e natureza. Nesse sentido, Froebel assim se manifesta em seu livro A educação do homem:

Nós concedemos espaço e tempo a plantas e animais jovens porque sabemos que, de acordo com as leis que vivem neles, eles se desenvolverão apropriadamente e crescerão bem; a animais e plantas jovens é dado o tempo necessário, e a interferência arbitrária nesse crescimento é evitada, porque é sabido que a prática oposta atrapalharia a pureza da manifestação da melodia do desenvolvimento; mas o jovem ser humano é observado como um pedaço de cera, uma porção de argila na qual o homem pode moldar o que ele desejar. Oh, homem, que vagueias através de jardim e campo, através de pasto e pomar, por que vós fechais vossa mente ao silencioso ensinamento da natureza? Olhe mesmo a planta silvestre, que cresce entre obstáculos e limitações, raramente produz uma indicação da lei interna; olhe-a na natureza, no campo ou no jardim, e veja como perfeitamente é conforme a lei - que vida interna pura ela mostra, harmoniosa em todas as partes e características: um sol bonito, uma estrela radiante surgiu da terra! Assim, pais, os seus filhos, os quais vocês forçam, em anos carinhosos, formas e objetivos contra sua natureza, e que por isso poderiam andar com vocês em uma deformidade mórbida e artificial - assim poderiam suas crianças também revelarse em beleza e desenvolver em harmonia completa! De acordo com as leis da influência divina e em vista do estilo e totalidade original do homem, toda educação arbitrária, prescritiva e categórica interferente na instrução e treinamento deve necessariamente aniquilar, prejudicar e destruir. [...] A representação livre e espontânea do divino no homem dá-se através da vida do homem, o que, como vimos, é o objetivo último e a razão de toda educação, tanto quanto o destino último do homem. (Froebel, 1887, p. 8-10, trad. minha)

Portanto, Lina só poderia ser uma criança exemplar, e sua história um poderoso veículo de difusão das idéias educacionais de Froebel. Lina passou pelo jardim-de-infância, instituição na qual o autor apli- cou em toda a sua plenitude todos os seus princípios educacionais, assim como o fez em Keilhau ${ }^{4}$. Por isso, segundo Liebschner (1992), não teria sido fácil para Froebel achar um nome adequado para esta instituição. Ele não queria utilizar a palavra "escola", pois esta traria o sentido de se estar colocando "coisas" na cabeça da criança, ensinando algo, e este não era o propósito daquela instituição, e sim guiar, orientar e cultivar nas crianças suas tendências divinas e sua essência humana, através do jogo, das ocupações e das atividades livres, tal como Deus faz com as plantas da natureza. Depois de procurar durante vários meses, o nome kindergarten (jardim de crianças) conseguiu unir todas essas idéias e princípios numa única e simples palavra. Estava criada a instituição na qual todos os preceitos até aqui expostos iriam ser aplicados em toda a sua plenitude, principalmente no que se refere ao respeito ao desenvolvimento da criança e à subordinação da educação ao estágio no qual se encontrasse tal desenvolvimento. Este recanto deveria ser entregue às mulheres, as quais, com coração de mãe, seriam as únicas capazes de cultivar nas criancinhas todos os seus talentos e todos os germes da perfeição humana unida a Deus.

${ }^{4} \mathrm{O}$ livro A educação do homem traz de forma detalhada o relato da experiência de Froebel na escola de Keilhau (fundada em 1817 e não dedicada exclusivamente à educação infantil, na qual trabalhou durante 13 anos), que possuía algumas características importantes, pois exemplificam de maneira mais clara como o seu trabalho ocorria no cotidiano. Nesta escola, adultos e crianças planejavam e estudavam juntos. Esse fator era importante, porque Froebel acreditava que tudo na escola deveria ser vivido; a vida era a melhor escola, a escola tinha de estar relacionada com a vida. Neste sentido, viver e escolarizar-se seriam sinônimos. A escola tinha as características de um internato, onde os alunos não só estudavam mas também se ocupavam das questões e problemas domésticos. Tudo deveria levar as crianças a pensar. As montanhas, as colinas e os rios serviam para o aprendizado da geografia, os insetos e as árvores para o de ciências naturais. O conhecimento necessariamente tinha de ter origem em algo que as crianças conhecessem e sobre o qual elas pudessem agir, manuseando, caminhando, modelando, desenhando, cantando etc. 
Então, fundado na natureza do homem e no seu instinto de formação e atividade, e conectado com a criação deste impulso, o objetivo desta instituição é ser um todo vivente, ou como se fosse uma árvore em si mesma, assim como promover meios de emprego e conseqüentemente de cultura e instrução fundados na relação do homem com a natureza e a vida; meios que, quando aplicados de uma maneira viva na criança desde o primeiro estágio do seu despertar espiritual e do uso de seus membros e sentidos, desenvolvam-se de todas as formas e, por isso, unidos entre si, com a natureza e com as leis da vida. [...] O objetivo desta instituição é suprir as necessidades e os requerimentos do mundo da criança, correspondentes ao presente estágio de desenvolvimento da humanidade e dar aos pais e adultos - os quais se encontram justamente na mencionada posição de cuidar da criação das crianças a eles confiadas jogos apropriados e meios de empregá-los e, consequientemente, instrução e cultivo - educação em geral - e, acima de tudo, meios adaptados para a mente, espírito e vida da criança: através disso, provar ser igualmente necessário, natural e recíproco o chamado humano das famílias: "venham, deixemo-nos viver com nossas crianças", para que esta seja tão grandiosa quanto é rica em bênçãos. (Froebel, 1917 , p. 13 e 17 , trad. minha)

Lina é uma criança exemplar, educada segundo desenvolvimento de Froebel dentro das duas instituições que ele mais prezava: o jardim-de-infância e a família.

\section{Conclusão - ou seria apenas um re-início?}

Froebel realizou descobertas pioneiras. Não podemos, entretanto, finalizar este trabalho sem apontar algumas reflexões críticas. Froebel, em toda a sua obra, procura conclamar as mulheres de sua época a assumirem a maternidade e a educação da primeira infância, insistindo na bênção que é ser mãe e na importância da criança como semente da divindade. Ele agita com força a bandeira levantada pelos puritanos, pelas campanhas de evangelização do povo, que auxiliaram no encerramento da "Era das Revoluções" por meio da adaptação do cotidiano familiar aos ditames da alienação imposta pela sociedade burguesa.
Vê-se que, no discurso de Froebel, mãe, criança e família tornaram-se abstratas, figuras idealizadas desligadas do ambiente social, econômico e político no qual estavam inseridas. A família, transformada em um mundo feminino e infantil, é santificada e passa a ser algo muito distante da vida pública, da qual apenas o homem adulto participa. Essa participação na vida pública não deve ser aqui entendida como participação de alguém que é sujeito de sua atividade e sujeito dos rumos tomados pela sociedade. Trata-se, isto sim, de uma submissão às relações de exploração, submissão esta da qual o homem adulto não pode fugir, pois isso significaria a ruína de sua família. A altivez que seria atribuída pela sua função de chefe dessa família idealizada é retirada dele em nome de seu dever de prover o sustento da família. O público passa a ser visto como algo pesado e perigoso do qual a família deve ser poupada e guardada. Assume-se que ser mãe é algo natural para a mulher, assim como é natural que o homem se ocupe da vida social. Os atributos angelicais com os quais mulher e criança são coroadas também se naturalizam. Homens, mulheres e crianças perdem o direito de decidirem sua função dentro da sociedade; ela já está predeterminada pelo divino e deve ser aceita. Isola-se a família dos conflitos sociais, entregando-a ao pragmatismo da vida cotidiana capitalista e à naturalização de suas relações. A culpa pelo fracasso ou as glórias pelo sucesso social passam a ser depositadas nos indivíduos, na constituição de suas famílias nucleares. Assim a burguesia mantém abertas as portas para explicar o sucesso demasiado de uns em detrimento do fracasso total de outros, tornando remotas, ao mesmo tempo, quaisquer possibilidades de lutas coletivas por parte dos "fracassados". Froebel procura mostrar o caminho para o sucesso dentro desse modelo, que não vem sem sacrifícios: a adaptação e a alienação são o preço pago.

Froebel acaba por representar, no plano educacional, a face reacionária e alienante da ideologia liberal-burguesa. Ele não deixa de incorporar à sua pedagogia elementos da face progressista dessa ideologia, isto é, elementos da luta contra a ideologia medieval. Mas, assim como a burguesia acabou por trair 
os ideais iluministas, ela terminou por trair a luta pela razão e pela ciência, adotando irracionalismos e misticismos que se mostrassem adequados à manutenção da ordem social burguesa, da mesma forma como a pedagogia de Froebel o fez. Ainda que apresente elementos progressistas, como a valorização do saber originário da observação das leis da natureza em oposição ao saber medieval, fruto da revelação mediatizada pelas autoridades eclesiásticas, esses elementos não frutificam, nessa pedagogia, numa concepção verdadeiramente imanentista da história e da sociedade. Ao contrário, acabam reforçando o pragmatismo alienado e alienante da cotidianidade capitalista, retirando desse pragmatismo qualquer possibilidade de evolução para uma concepção materialista da história, e tornando-o aliado do moralismo cristão.

O leitor poderia questionar o fato de não ter sido mencionado que o discurso educacional de nosso autor aparece como uma evolução, um progresso em relação ao ensino escolástico. O fato é que se pode considerá-lo como um avanço e um retrocesso: avanço porque abre a possibilidade de busca de um conhecimento que não esteja preso às revelações, à verdade absoluta, aos livros ditados pelos que receberam a revelação divina; retrocesso porque, em vez de serem utilizados os conhecimentos científicos que estavam sendo produzidos, calcando-se o ensino na razão e na ciência, opera-se um esvaziamento completo do indivíduo, cria-se uma espécie de ojeriza a toda forma de cultura mais elevada. Agora não é mais Deus que revela o conhecimento a seus escolhidos (a hierarquia eclesiástica), mas cada indivíduo deve procurar em seu interior e no seu exterior o que realmente lhe é útil e viável de ser conhecido. Não se pode esquecer que o papel divinizante e eterno permanece, bem como o forte discurso moralizante, e não basta o indivíduo repetir orações memorizadas ou penitenciarse nas igrejas, mas ele deve viver a santidade em seu dia-a-dia, obedecer aos desígnios divinos que não vêm mais de fora, mas estão implantados na essência de sua individualidade. O indivíduo deve, portanto, constituir exemplo de virtude, assim como o fez Jesus Cristo, filho de Deus. Uma questão que está ainda por ser investigada mais pormenorizadamente é a das continuidades e rupturas entre esse "naturalismo cristão" na pedagogia froebeliana e o naturalismo cientificista da pedagogia escolanovista do começo do século XX. Talvez eu possa encontrar algumas pistas nesse sentido no estudo que venho realizando, com apoio do $\mathrm{CNPq}$, dos trabalhos de Montessori e Claparède.

Embora não seja objetivo deste artigo traçar o percurso da difusão das idéias de Froebel por todo o mundo, por meio dos jardins-de-infância, ao longo dos séculos XIX e XX, assinalo, apenas a título de constatação inicial, que encontrei na história da alfabetização de Lina os germes dos ideais que mais tarde viriam a nortear o movimento escolanovista, que podem ser expressos nos seguintes princípios educacionais anteriormente descritos:

a) a criança e seu desenvolvimento passariam a ser o centro do processo educacional, a espontaneidade infantil deveria ser preservada a todo custo. A tarefa do educador seria similar à do jardineiro, cultivando as forças espirituais imanentes da criança;

b) a atividade seria o ponto central de toda a metodologia de trabalho, atividade esta que deveria sempre se centrar nos interesses e necessidades da criança, respeitando seu ritmo natural de desenvolvimento. A educação escolar deveria ser, portanto, ativa. Não por acaso os métodos escolanovistas foram chamados de métodos ativos. Juntamente com isso, vemos a apologia das atividades manuais e práticas imprescindíveis tanto para o desenvolvimento intelectual quanto para o desenvolvimento moral;

c) a disciplina exterior seria substituída pelo cultivo da disciplina interior;

d) a preocupação com a transmissão de conteúdos escolares seria substituída pela criação do máximo de possibilidades de desenvolvimento das habilidades e capacidades de cada criança, com a ajuda do trabalho, do amor e da ale- 
gria. Neste ponto Froebel não deixa de defender o lema "aprender a aprender" 5 em sua forma embrionária.

A idéia de que a educação infantil é um solo fértil para a difusão de concepções psicológicas e pedagógicas centradas na atividade espontânea da criança já foi apresentada por Coll (1994, p.45-46). Quando este autor afirma que a educação pré-escolar, ao contrário dos outros níveis de ensino, nunca conseguiu encaixar-se nas estruturas tradicionais de ensino, isto ocorreria por este tipo de atendimento possuir características especiais, como a idade dos alunos, o que obrigaria a uma flexibilização curricular, já que conteúdos conceituais amplos não poderiam ser ensinados. "Estes fatores, junto com a não-obrigatoriedade do ensino pré-escolar, explicam o fato de que a maior parte das propostas pedagógicas de natureza progressista e renovadora tenham tradicionalmente um impacto privilegiado neste nível de ensino." Por isso, afirma o autor, não é de se estranhar que a Pedagogia Ativa tenha suas raízes na educação pré-escolar; afinal, "a importância da atividade do aluno é um postulado que a quase totalidade dos educadores de jardim-de-infância aceita" (Coll, 1994, p.45-46). Há aí todo um vasto campo de estudos sobre a história da Educação Infantil, desde o pioneirismo de Froebel até os dias atuais. Este artigo é apenas uma contribuição neste sentido.

ALESSANDRA ARCE é doutora em educação pela UNESP Araraquara e atualmente vincula-se, como bolsista recém-doutora do CNPq, ao Departamento de Filosofia e História da Educação e ao Grupo de Pesquisa História da Educação Brasileira da UNICAMP.

${ }^{5}$ Uma análise crítica da centralidade do lema "aprender a aprender” nos ideários pedagógicos contemporâneos é apresentada no capítulo 1 do livro Vigotski e o "aprender a aprender" (Duarte, 2002) e no artigo "As pedagogias do aprender a aprender e algumas ilusões da assim chamada sociedade do conhecimento" (Duarte, 2001).

\section{Referências bibliográficas}

ARCE, A., (1997). Jardineira, tia e professorinha: a realidade dos mitos. Dissertação de mestrado. Campo-Grande, MS: UFMS

(2001). Documentação oficial e o mito da educadora nata na educação infantil. Cadernos de Pesquisa, $\mathrm{n}^{\circ} 113$, julho, p.167-184.

(2002a). A pedagogia na "Era das Revoluções": uma análise do pensamento de Pestalozzi e Froebel. Campinas: Autores Associados.

, (2002b). Friedrich Froebel: o pedagogo dos jardinsde-infância. Petrópolis: Vozes.

BASTOS, M. H. C., (2001). Jardim de crianças: o pioneirismo do Dr. Menezes Vieira (1875-1887). In: MONARCHA, C. (org.). Educação da infância brasileira (1875-1983). Campinas: Autores Associados / São Paulo: FAPESP, p. 31-80.

BLOW, S., (1895). Introduction: Froebel's philosophy. In: FROEBEL, F. The mottoes and commentaries of Friedrich Froebel's mother play. Translated by Henrietta R. Eliot and Susan Blow. New York and London: D. Appleton, p. 1-52.

COLE, P. R., (1907). Herbart and Froebel: an attempt at synthesis. New York: Teachers College / Columbia University.

COLL, C. S., (1994). Aprendizagem escolar e construção do conhecimento. Porto Alegre: Artes Médicas.

DUARTE, N., (2001). As pedagogias do "aprender a aprender" e algumas ilusões da assim chamada sociedade do conhecimento. Revista Brasileira de Educação, n. 18, set./dez., p. 1-8.

, (2002). Vigotski e o “aprender a aprender": crítica às apropriações neoliberais e pós-modernas da teoria vigotskiana. $2^{\mathrm{a}}$ ed. Campinas: Autores Associados.

FROEBEL, F., (1902). Education by development: the second part of the pedagogics of the kindergarten. Translated by Josephine Jarvis. New York and London: D. Appleton.

(1887). The education of man. New York: D. Appleton.

(1895). The mottoes and commentaries of Friedrich Froebel's mother play. Translated by Henrietta R. Eliot and Susan Blow. New York and London: D. Appleton. 
(1917). Pedagogics of the kindergarten. Translated by Josephine Jarvis. New York and London: D. Appleton.

, (2001). A educação do homem. Tradução de Maria Helena C. Bastos. Passo Fundo, RS: EdUPF.

HOBSBAWM, E., (1996). A Era das Revoluções (1789-1848). $10^{\mathrm{a}}$ ed. Trad. Marcos Santarrita. Rio de Janeiro: Paz e Terra

KISHIMOTO, Tiziko M., (1986). A pré-escola em São Paulo; das origens a 1940. São Paulo: Loyola.

KOCH, D., (1982). Friedrich Froebel, o criador do jardim-de-infância, no seu bicentenário. Convivium, v. 21, n. 25, p. 45-63. , (1985). Desafios da educação infantil. São Paulo: Loyola

KUHLMANN, M., (2001a). As grandes festas didáticas: a educação brasileira e as exposições internacionais, 1862-1922. São Paulo: São Francisco/CDAPH.

, (2001b). O jardim-de-infância e a educação das crianças pobres: final do século XIX, início do século XX. In: MONARCHA, C. (org.). Educação da infância brasileira (1875-1983). Campinas: Autores Associados / São Paulo: FAPESP. p. 3-30.

KUHLMANN, M., BARBOSA, M. C., (1998). Pedagogia e rotinas no jardim-de-infância. In: KUHLMANN, M. Infância e educação infantil; uma abordagem histórica. Porto Alegre: Mediação.
LIEBSCHNER, J., (1992). A child's work: freedom and guidance in Froebel's educational theory and practice. Cambridge: The Lutterworth Press.

MARENHOLZ-BULÖW, B. B., (1877). Reminiscences of Friedrich Froebel. Translated by Horace Mann. Boston: Lee and Shepard.

MICHELET, J., (1985). La mujer. Traducción Stella Mastrangelo. México: Fondo de Cultura Econômica.

MONARCHA, C., (2001). "Revista do Jardim-de-infância”: uma publicação exemplar. In: MONARCHA, C. (org.). Educação da infância brasileira (1875-1983). Campinas: Autores Associados / São Paulo: FAPESP. p. 81-120.

PERROT, M., (1991). A família triunfante. In: DUBY, G., ARIÈS, P. (orgs.). História da vida privada: da revolução francesa à primeira guerra. $5^{\mathrm{a}}$ ed. São Paulo: Companhia das Letras, v. 4. p. $93-104$

PINAZZA, M. A., (1997). A pré-escola paulista á luz das idéias de Pestalozzi e Froebel: memória reconstruída a partir de periódicos oficiais. Tese de doutorado. São Paulo: USP.

PRÜFER, J., (1930). Frederico Froebel. Barcelona / Buenos Aires: Labor

Recebido em junho de 2002

Aprovado em setembro de 2002 
visualizar, no registro dos livros de ocorrência, elementos produtores de cenários criminosos e pecaminosos no cotidiano escolar, naquilo que podem expressar em termos das práticas confessionais de tipo jurídico e religioso. Do ponto de vista jurídico, a confissão é vista em algumas de suas possíveis articulações com outros elementos presentes no relato dos livros, como testemunhos, provas, indícios, fazendo parte de uma espécie de miniinquérito diário da escola, produtor de acusações, crimes e penas. Do ponto de vista religioso, a dinâmica confessional é vista através desses livros como parte de um processo de circulação de pecados, em que a tradicional batalha do Bem contra o Mal, de Deus contra o Diabo, é apresentada e, de certa forma, ensinada.

Palavras-chave: disciplina escolar, cultura escolar, confissão.

\section{Criminal and sinful scenarios in the registers of occurrences of a public school in Curitiba}

The text identifies relations between the theme of confession and the narration extant in the recent registers of occurrences of a public school in Curitiba, based on post-structuralist analytical references. These registers relate cases of students considered by the school as problematic and undisciplined and contain 517 occurrences for the years 1998 and 1999. In the records of the registers, we focus on elements that produce criminal and sinful scenarios in daily school life, with regard to that which they may express in terms of confessional practices of a juridical and religious type. From the juridical point of view, confession is seen in some of its possible articulations with other elements present in the narrative of the registers, like evidence, proof, clues, making part of a kind of daily miniinquiry of the school, and in so doing producing accusations, crimes and punishment. From the religious point of view, the confessional dynamic is seen through these registers as a part of the process of "circulation of sins", in which the traditional battle between Good and Evil, between God and the Devil, is presented and, in a certain way, taught.

Key-words: school discipline, school culture, confession.

\section{Alessandra Arce}

Lina, uma criança exemplar! Friedrich Froebel e a pedagogia dos jardins-de-infância

O presente trabalho dedica-se a analisar um importantíssimo texto de Friedrich Froebel (1782-1852), fundador dos jardins-de-infância (kindergartens): "De como Lina aprendeu a escrever e a ler: Uma história para crianças que gostam de estar ocupadas". O texto expõe, na forma escrita de uma historinha, os mais importantes princípios educacionais de Froebel. O objetivo foi apresentar, a partir da historinha, as idéias do autor a respeito de como se deve pensar e fazer educação para infância. Retomou-se as idéias de um dos pioneiros da educação de crianças menores de 6 anos, por considerar-se que sua teoria educacional traz os germens das discussões atuais que são travadas em prol da construção de uma pedagogia da educação infantil. Palavras-chave: Friedrich Froebel, jardim-de-infância, historia da educação.

Lina, a wonderful child! Friedrich Froebel and the pedagogy of

\section{kindergartens}

This work analyses an important text written by Friedrich Froebel (17821852), creator of the Kindergartens. The text, entitled "On how Lina learnt to read and write: a story for children who like to be busy", explains, in story form, the most important educational principles of Froebel. The aim of this paper is to present the ideas of the author with regard to how one ought to think and practice education for early childhood, taking the story as the starting point. The ideas of one of the pioneers of education for early childhood (children of less than six years of age) are re-discussed since it is considered that his educational theory presents the seeds for current discussions in favour of constructing a Pedagogy for Child Education. Key-words: Friedrich Froebel, kindergarten, educational history.

\section{Nelson De Luca Pretto}

Formação de professores exige rede! $\mathrm{O}$ analisa as políticas públicas de comunicação e de educação, com ênfase na formação de professores. Os projetos governamentais na área de educação a distância, especialmente o Programa TV Escola e o PROINFO, são analisados identificando a distância que existe entre os planos governamentais e a realidade educacional brasileira. Fica evidente, no discurso oficial, que, em última instância, se as políticas não derem certo, a culpa será sempre do professor. Isso vem se dando em razão da desvalorização continuada do professorado, reforçada contemporaneamente com a implantação de programas de educação a distância para a formação de professores. Na maioria das vezes, isso se dá de forma aligeirada e superficial, preocupando-se os programas, em última instância, apenas com a certificação dos professores para atender à LDB. Em oposição a isso, enfatiza-se a necessidade de fortalecimento da escola e do professor através de, entre outras coisas, oferecimento de sólida formação e da melhoria das condições de trabalho, incluindo aí a necessária presença das Tecnologias da Informação e Comunicação (TIC). Na análise dessa políticas, evidencia-se a distância do MEC do sistema público de ensino superior, em es- 